\title{
Comparison of breakfast consumption in rural and urban among Inner Mongolia Medical University students
}

\author{
Teer $\mathrm{Ba}^{1}$, He Yi ${ }^{1}$, Zhiyue Liu ${ }^{1}$, Zhijun $\mathrm{Li}^{1}$, Wenfang Guo ${ }^{1}$, Yuki Eshita ${ }^{2}$, Juan Sun ${ }^{1^{*}}$ \\ ${ }^{1}$ Department of Public Health, Inner Mongolia Medical College, Hohhot, China; \\ *Corresponding Author: cnsunjuan@yahoo.com.cn \\ ${ }^{2}$ Faculty of Medicine, Oita University, Oita, Japan
}

Received 29 April 2013; revised 30 May 2013; accepted 10 June 2013

Copyright (C) 2013 Teer Ba et al. This is an open access article distributed under the Creative Commons Attribution License, which permits unrestricted use, distribution, and reproduction in any medium, provided the original work is properly cited.

\begin{abstract}
Objective: The aim of current study was to investigate breakfast consumption between rural and urban among Inner Mongolia Medical University students, China. Method: From December 2010 to January 2011, a cross-sectional survey was conducted among medical students in the Inner Mongolia Medical University using a self-administered questionnaire. X2 was used to identify the differences between rural and urban. Result: The prevalence of breakfast consumption was $70.95 \%$. The prevalence of breakfast in rural was higher than that in urban $\mathbf{( 7 2 . 0 9 \%}$ vs. $69.78 \%$ ). Breakfast consumption prevalence among male students in rural was higher $7.4 \%$ than those of students in urban. Students in Mongolian ethnic in rural were more likely to eat breakfast than Mongolian students in urban. The prevalence of breakfast decreases with grade increase both urban and rural. Students with good physical condition were more likely to eat breakfast compared with students with poor physical condition. Conclusion: The prevalence of regular breakfast consumption in rural was higher than that in urban. However, the prevalence of eating breakfast declined faster in rural than that in urban. Our study findings could help health care professionals develop targeted interventions designed to increase breakfast consumption.
\end{abstract}

Keywords: Breakfast Consumption; Rural; Urban; Medical Students

\section{INTRODUCTION}

Many countries have been confirmed that to eat breakfast has an important role on health [1-4]. One study provides valuable information about irregular breakfast eating among adolescents, which is associated with a low frequency of health promoting behavior.

In different regions, breakfast consumption habits varied considerably [5]. In Asia a decline in regular breakfast consumption has been reported. Approximately $10 \%$ of school-aged children and adolescents in Hong Kong skipped breakfast at least 4 times a week [6] and in Malaysia, breakfast was the most frequently missed meal [7]. It was reported that there were differences of eating breakfast between urban and rural and the prevalence of breakfast in urban was higher than that in rural [8]. Some studies showed that there were grade differences of eating breakfast. High percentages of high school students (18\%) also miss breakfast with the just $4 \%$ in elementary school children [9]. Breakfast consumption was significantly lower among older students as compared to younger students [10]. It was reported that there were gender differences of eating breakfast in different regions and it was common among adolescents, especially girls $[11,12]$.

In China university students often pay insufficient attention to breakfast, with some individuals missing breakfast because it takes too much time [13]. Moreover, different population lifestyle habits may relate to breakfast consumption habits [14].

Based on recent breakfast research and our previous study about the prevalence of skipping breakfast and the factors associated with this among Inner Mongolia medical students [14], our current survey was further discussing the prevalence of breakfast in genders, ethnics 
and physical condition levels between urban and rural among Inner Mongolia medical students. A longer-term goal was to use the survey results to assist with design of interventions to change breakfast consumption habits among medical university students.

\section{METHODS}

\subsection{Questionnaire and Measures}

A cross-sectional survey was conducted among medical students at the Inner Mongolia Medical College of China who resided on campus at the time of the survey. The survey focused on medical students and employed a self-administered questionnaire [15].

Students completed the questionnaires in the classroom. A member of our study group explained the purpose of the survey. When students filled out the questionnaire participants returned the questionnaire in a sealed envelope to members of our study group. The questionnaire contained basic demographic data including sex, ethnicity and residence and regarding breakfast consumption habits of the participants during time at university.

According to our previous study regular breakfast eating was defined as Nutrition Dietary Assessment, which is any food or beverage consumption between awakening and 45 minutes after the start of school [14].

A total 6044 students including Grades 1, 2, 3, 4 and 5 from the Inner Mongolia Medical University campus completed the questionnaire. We defined students who came from a city or suburb as urban, and those from a village or pastoral area as rural. Physical condition was evaluated similarly, with possible responses of good to bad [14]. In our current study we define the medium and bad consolidated as poor. Among all ethnicities we mainly discuss information in the Mongolian and Han ethnics.

\subsection{Statistical Analysis}

$\mathrm{X}^{2}$ test was performed on breakfast consumption differences between urban and rural among genders, ethnicities and physical conditions. The trend line in Grades $1,2,3,4$ and 5 used to describe changes of prevalence of breakfast between urban and rural.

Quantitative data were entered using EpiDate (EpiData Association, Denmark; v3.1). For all analyses, we used SPSS for Windows v13.0. A two-tailed $\mathrm{P}<0.05$ was considered statistically significant.

\subsection{Ethical Approval}

Ethical approval to conduct the study was obtained from the Ethical Committee of Inner Mongolia.

\section{RESULTS}

A total of 6019 students answered breakfast and region questions. 2483 students were in urban and 3536 students were in rural. The prevalence of breakfast consumption was $70.95 \%$. The prevalence of breakfast in rural was higher than that in urban $(72.09 \%$ vs. $69.78 \%)$.

Breakfast consumption prevalence in urban and rural respectively showed in Table 1 . Breakfast prevalence between Mongolian and Han ethnic groups was not significantly different both in urban and rural. However compared with female students the male students were less likely to eat breakfast regularly both in urban and rural. Students with good physical fitness were more likely to eat breakfast compared with students with poor physical fitness.

Table 2 showed the differences of breakfast consump-

Table 1. Prevalence of breakfast among Inner Mongolia Medical University students in urban and rural.

\begin{tabular}{|c|c|c|c|c|}
\hline & \multicolumn{3}{|c|}{ Rural n (\%) } & \multirow{2}{*}{$\begin{array}{c}\text { Urban n (\%) } \\
\text { Skipping }\end{array}$} \\
\hline & Breakfast & Skipping & Breakfast & \\
\hline Male & $637(61.37)$ & $401(38.63)$ & $393(54)$ & $335(46)$ \\
\hline Female & 1913 (76.6) & $585(23.4)$ & $1341(76.4)$ & $414(23.6)$ \\
\hline$X^{2}$ & 83.397 & & 122.853 & \\
\hline $\mathrm{P}$ & $<0.001$ & & $<0.001$ & \\
\hline Mongolian & $669(73.5)$ & $241(26.5)$ & 332 (67.9) & $157(32.1)$ \\
\hline Han & 1773 (71.6) & $702(29.4)$ & $1302(71.3)$ & $524(29.7)$ \\
\hline$X^{2}$ & 1.17 & & 2.16 & \\
\hline $\mathrm{P}$ & 0.28 & & 0.14 & \\
\hline Good & $1621(75.2)$ & $536(24.8)$ & $1042(73.2)$ & $381(26.8)$ \\
\hline$X^{2}$ & 25.676 & & 18.46 & \\
\hline $\mathrm{P}$ & $<0.001$ & & $<0.001$ & \\
\hline
\end{tabular}


Table 2. Prevalence of breakfast consumption among Inner Mongolia Medical University students between urban and rural.

\begin{tabular}{|c|c|c|c|c|}
\hline & Rural n (\%) & Urban n (\%) & $\mathrm{X}^{2}$ & $\mathrm{P}$ \\
\hline \multicolumn{5}{|c|}{ Gender $(n=4284)$} \\
\hline Male & $637(61.4)$ & $393(54.00)$ & 9.59 & 0.02 \\
\hline Female & $1913(76.6)$ & $1341(76.4)$ & 0.017 & 0.897 \\
\hline \multicolumn{5}{|c|}{ Ethnicity $(n=4076)$} \\
\hline Han & $1773(71.6)$ & $1302(71.3)$ & 0.057 & 0.811 \\
\hline Mongolian & $669(73.5)$ & $332(67.9)$ & 4.94 & 0.026 \\
\hline \multicolumn{5}{|c|}{ Physical condition $(n=4273)$} \\
\hline Good & $1621(75.2)$ & $1042(73.2)$ & 1.67 & 0.197 \\
\hline Poor & $922(67.3)$ & $688(65.2)$ & 1.162 & 0.28 \\
\hline
\end{tabular}

tion between urban and rural among different genders, ethnics and physical condition levels. There was no significantly different in breakfast consumption prevalence between urban female and rural female. However, prevalence of breakfast consumption among male students in rural was higher $7.4 \%$ than those of student in urban. Students in Mongolian ethnic in rural was more likely to eat breakfast than Mongolian students in urban.

Figure 1 shows the grade trend of eating breakfast in males between rural and urban. The prevalence of breakfast decreases with grade increase both urban and rural. However, breakfast consumption prevalence decline fastest in grade five of rural students than those of urban students.

Figure 2 shows the grade trend of eating breakfast between rural Mongolian students and urban Mongolian students. The prevalence of breakfast decreased faster in rural areas than that in urban areas from the grade second to grade five and the grade five declined fastest in rural.

\section{DISCUSSION}

Inner Mongolia has vast territory and long nomadic history, which cause the imbalance development between rural area and city area, so there is a large difference in living environment between rural area and urban area [15]. Previous one study had confirmed there were differences of eating breakfast between rural and urban areas [11]. Our current study discussed the different of breakfast consumption between rural and urban in Inner Mongolian medical university.

Our study showed that the prevalence of eating breakfast in rural $(72.09 \%)$ was higher than that in urban $(69.78 \%)$. Similarly, in Maryland urban students were more than twice as likely to skip breakfast compared with rural students [16]. The prevalence of eating breakfast in our study in rural was higher than that in United States 42.2\% [11] and in Croatian 23.0\% [17].

The differences of eating breakfast between urban and rural mainly were in male students and Mongolian stu-

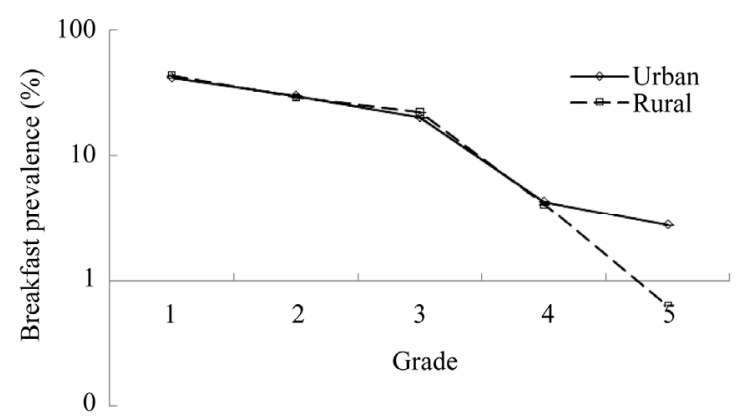

Figure 1. Breakfast eating rate changes in male students in Inner Mongolia Medical University.

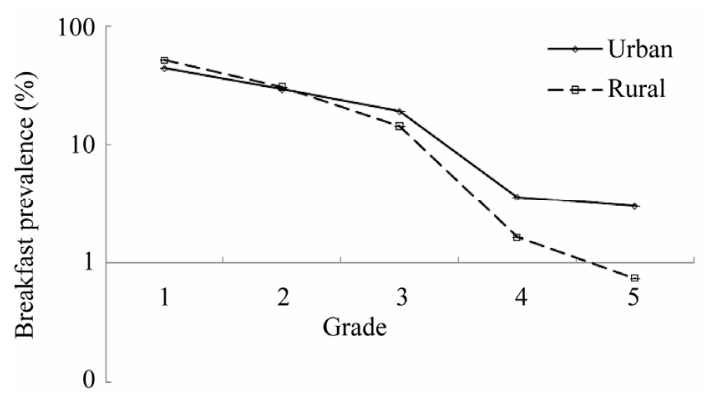

Figure 2. Breakfast eating rate changes in Mongolian students in Inner Mongolia Medical University.

dents. Prevalence of breakfast was higher in rural than in urban probably because different life style may result in different breakfast habits [18]. Mongolian students in rural were more able to eat breakfast than Mongolian students in urban. The reason may be Mongolians living in rural areas with more original breakfast habits while living in the urban becoming accustomed to the urban lifestyle. Those findings suggest that we should take measures to encourage male students and Mongolian students in urban to eat breakfast regularity.

Our previous study showed that prevalence of skipping breakfast was highest on Grade 5 [14]. Our current study showed similar result that the prevalence of breakfast decreases with grade increase especially on grade 
four and five of rural. Rural prevalence of breakfast declining is faster than that of urban probably because rural students have more stress such as fear of failing, finance problem causing rural more stress [19]. Moreover, one study has shown significant relationships between skipping breakfast and depressive symptoms, stress [20]. Such rural students in grade four and five were more likely to skipping breakfast. This find suggested that school administrators should take intervention measures to improve the breakfast consumption of grade four and five especially rural students.

Our previous studies showed that poor physical condition status most likely have a higher prevalence of obese and those individuals who skip breakfast are more likely to be obese compared to students who eat breakfast regularly [21]. Our current study also confirmed that poor physical fitness status most likely have a higher prevalence of skipping breakfast whether students from rural or urban. Previous studies have shown that breakfast consumption was important for maintaining adequate nutrient intake and health [22,23]. Breakfast skipping deserves attention in preventive programs [12]. Health educators need to explore new ways to encourage regular breakfast consumption and health life style among students in all regions $[16,24,25]$.

\section{CONCLUSION}

The prevalence of regular breakfast consumption was different between urban and rural. The prevalence of eating breakfast in rural was higher than that in urban. However, the prevalence of eating breakfast on grade four and five declined faster in rural than that in urban. Our study findings could help health care professionals develop targeted interventions designed to increase breakfast consumption.

\section{REFERENCES}

[1] Chaplin, K. and Smith, A.P. (2011) Breakfast and snacks: Associations with cognitive failures, minor injuries, accidents and stress. Nutrients, 3, 515-528. doi:10.3390/nu3050515

[2] Hoyland, A., Dye, L. and Lawton, C.L. (2009) A systematic review of the effect of breakfast on the cognitive performance of children and adolescents. Nutrition Research Reviews, 22, 220-243. doi:10.1017/S0954422409990175

[3] Sandercock, G.R., Voss, C. and Dye, L. (2010) Associations between habitual school-day breakfast consumption, body mass index, physical activity and cardiorespiratory fitness in English schoolchildren. European Journal of Clinical Nutrition, 64, 1086-1092. doi:10.1038/ejen.2010.145

[4] Rampersaud, G., Pereira, M.A., Girard, B., Adams, J. and Metzl, J. (2005) Breakfast habits, nutritional status, body weight and academic performance in children and adole- scents. Journal of the American Dietetic Association, 105, 743-760. doi:10.1016/j.jada.2005.02.007

[5] Isaksson, H., Rakha, A., Andersson, R., Fredriksson, H., Olsson, J. and Åman, P. (2011) Rye kernel breakfast increases satiety in the afternoon-An effect of food structure. Nutrition Journal, 10, 1-10.

doi:10.1186/1475-2891-10-31

[6] So, H.K., Nelson, E.A.S., Li, A.M., Guldan, G.S. and Yin, J. (2011) Breakfast frequency inversely associated with BMI and body fatness in Hong Kong Chinese children aged 9 - 18 years. British Journal of Nutrition, 106, 742751. doi:10.1017/S0007114511000754

[7] Moy, F.M., Gan, C.Y. and Kassim, S.Z.M. (2006) Eating patterns of school children and adolescents in Kuala Lumpur. Journal of Nutrition, 12, 1-10.

[8] Mushtaq, M.U., Gull, S., Mushtaq, K., Shahid, U. And Shad, M.A. (2011) Dietary behaviors, physical activity and sedentary lifestyle associated with overweight and obesity, and their socio-demographic correlates, among Pakistani primary school children. International Journal of Behavioral Nutrition and Physical Activity, 8, 130. doi:10.1186/1479-5868-8-130

[9] Howden, J.A., Chongl, Y.H. and Leung, S.F. (1993) Breakfast practices in the Asian region. Asia Pacific Journal of Clinical Nutrition, 2, 77-84.

[10] Arora, M., Nazar, G.P., Gupta, V.K., Perry, C.L., Reddy, K.S. and Stigler, M.H. (2012) Association of breakfast intake with obesity, dietary and physical activity behavior among urban school-aged adolescents in Delhi, India: Results of a cross-sectional study. BMC Public Health, 12, 881.

[11] Sharkey, J.R., Johnson, C.M. and Dean, W.R. (2011) Lesshealthy eating behaviors have a greater association with a high level of sugar-sweetened beverage consumption among rural adults than among urban adults. Food \& Nutrition Research, 55, 372. doi:10.3402/fnr.v55i0.5819

[12] Vereecken, C. and Rasmussen, M. (2009) Breakfast consumption and its socio-demographic and lifestyle correlates in school children in 41 countries participating in the HBSC study. International Journal of Public Health, 54, 180-190. doi:10.1007/s00038-009-5409-5

[13] Zeng, Y.-C., Li, S.-M., Xiong, G.-L., Su, H.-M. and Wan, J.-C. (2011) Influences of protein to energy ratios in breakfast on mood, alertness and attention in the healthy undergraduate students. Health, 3, 383-393. doi:10.4236/health.2011.36065

[14] Sun, J., Yi, H. and Liu, Z.Y. (2013) Factors associated with skipping breakfast among Inner Mongolia medical students in China. BMC Public Health, 13, 42.

[15] Bian, J., Du, M., Liu, Z., Fan, Y., Eshita, Y. and Sun, J. (2012) Prevalence of and factors associated with daily smoking among Inner Mongolia medical students in China: A cross-sectional questionnaire survey. Substance Abuse Treatment, Prevention, and Policy, 7, 20. doi:10.1186/1747-597X-7-20

[16] Gross, S.M., Bronner, Y., Welch, C., Dewberry-Moore, N. and Paige, D.M. (2004) Breakfast and lunch meal skipping patterns among fourth-grade children from selected 
public schools in urban, suburban, and rural maryland. Journal of the American Dietetic Association, 104, 420423. doi:10.1016/j.jada.2003.12.014

[17] Baric, I.C. and Šatalić, Z. (2003) Breakfast food patterns among urban and rural Croatian schoolchildren. Nutrition and Health, 17, 29-41. doi:10.1177/026010600301700104

[18] Keski-Rahkonen, A., Kaprio, J., Rissanen, A., Virkkunen, M. and Rose, R.J. (2003) Breakfast skipping and healthcompromising behaviors in adolescents and adults. European Journal of Clinical Nutrition, 57, 842-853. doi:10.1038/sj.ejen.1601618

[19] Pillay, A.L. (2010) Sources of stress and support among rural-based first-year university students: An exploratory study. South African Journal of Psychology, 40, 234-240. doi:10.1177/008124631004000302

[20] Blackie, C., Gregg, R. and Freeth, D. (1998) Promoting health in young people. Nursing Standard, 12, 39-46.

[21] Bian, J. (2012) Prevalence of and factors associated with various level of body weight among Inner Mongolia medical students in China. Open Journal of Preventive
Medicine, 2, 123-130. doi:10.4236/ojpm.2012.22018

[22] Kant, A.K., Andon, M.B., Angelopoulos, T.J. and Rippe, J.M. (2008) Association of breakfast energy density with diet quality and body mass index in American adults: National health and nutrition examination surveys, 19992004. The American Journal of Clinical Nutrition, 88, 1396-1404.

[23] Williams, P. (2005) Breakfast and the diets of Australian adults: An analysis of data from the 1995 national nutrition survey. International Journal of Food Sciences and Nutrition, 56, 65-79. doi:10.1080/09637480500082108

[24] Yang, R.-J., Wang, E.K., Hsieh, Y.-S. and Chen, M.-Y. (2006) Irregular breakfast eating and health status among adolescents in Taiwan. BMC Public Health, 6, 295. doi:10.1186/1471-2458-6-295

[25] Boo, N.Y., Chia, G.J., Wong, L.C., Chew, R.M., Chong, W. and Loo, R.C. (2010) The prevalence of obesity among clinical students in a Malaysian medical school. Singapore Medical Journal, 51, 126-132. 